INFLAMMATORY BOWEL DISEASE

\title{
Comparison of magnetic resonance imaging colonography with conventional colonoscopy for the assessment of intestinal inflammation in patients with inflammatory bowel disease: a feasibility study
}

\author{
A G Schreyer, H C Rath, R Kikinis, M Völk, J Schölmerich, S Feuerbach, G Rogler, J Seitz, \\ H Herfarth
}

See end of article for authors' affiliations

.....................

Correspondence to: $\operatorname{Dr}$ A G Schreyer, Department of Rádiology, University Hospital, Regensburg, 93042 Regensburg, Germany; andreas.schreyer@ klinik.uni-regensburg.de

Revised version received 11 March 2004 Accepted for publication 16 March 2004

\begin{abstract}
Aim: Magnetic resonance imaging (MRI) based colonography represents a new imaging tool which has mainly been investigated for polyp screening. To evaluate this approach for patients with inflammatory bowel disease (IBD), we compared MRI based colonography with conventional colonoscopy for assessing the presence and extent of colonic inflammation.

Patients and methods: In 22 consecutive patients with suspected or known IBD, MRI colonography was performed immediately before conventional colonoscopy. After bowel cleansing, a Tl positive contrast agent was applied rectally. In addition to T2 weighted sequences, $\mathrm{T} 1$ weighted two dimensional and three dimensional Flash acquisitions as well as volume rendered virtual endoscopy were performed. All images were evaluated with regard to typical MRI features of inflammation. The results were compared with colonoscopy findings.

Results: Distension and image quality was assessed as good to fair in $97.4 \%$ of all colonic segments. Only four of 154 segments were considered non-diagnostic. With colonoscopy serving as the gold standard, the sensitivity for correctly identifying inflammation on a per segment analysis of the colon was $31.6 \%$ for Crohn's disease (CD) and 58.8\% for ulcerative colitis (UC). In CD, in most cases mild inflammation was not diagnosed by MRI while in UC even severe inflammation was not always depicted by MRI. Virtual endoscopy did not add any relevant information.

Conclusion: MRI based colonography is not suitable for adequately assessing the extent of colonic inflammation in patients with IBD. Only severe colonic inflammation in patients with CD can be sufficiently visualised.
\end{abstract}

MRI based colonography to assess the presence and location of inflammation in patients with IBD.

\section{MATERIALS AND METHODS \\ Patients}

Our study was performed prospectively in 22 consecutive patients (aged 19-71 years (median 38 years); 11 males, 11 females) with highly suspected or known IBD, between August 2001 and April 2002. All patients with Crohn's disease (CD) were classified according to the Vienna classification. ${ }^{10}$ The study protocol was approved by our institutional review board and written informed consent was obtained from all patients. All patients included in this study were adult patients with no contraindications for MRI, scheduled for a conventional colonoscopy to assess disease activity or pathological changes of the colon.

\section{MRI}

Bowel preparation was performed in all patients using macrogol 3350 (Klean-Prep; Norgine, Marburg, Germany). MRI colonography was carried out the same day before conventional colonography. Approximately 1.5 litre (range 1.1-1.8 litres, mean 1.5 litres) of a gadolinium/water mixture with a concentration of $5 \mathrm{mmol} / \mathrm{l}$ gadolinium-DTPA

Abbreviations: $M R$, magnetic resonance; $M R I$, magnetic resonance imaging; IBD, inflammatory bowel disease; $C T$, computed tomography; $C D$, Crohn's disease; UC, ulcerative colitis 


\begin{tabular}{|c|c|c|c|c|c|c|}
\hline $\begin{array}{l}\text { Patient } \\
\text { No }\end{array}$ & $\begin{array}{l}\text { Age } \\
\text { (y) }\end{array}$ & Sex & $\begin{array}{l}\text { Disease } \\
\text { (months) }\end{array}$ & $\begin{array}{l}\text { Suspected or } \\
\text { known } \\
\text { diagnosis }\end{array}$ & Final diagnosis & $\begin{array}{l}\text { Disease extent } \\
\text { (UC) }\end{array}$ \\
\hline 1 & 44 & M & 244 & UC & UC & Pancolitis \\
\hline 2 & 30 & M & 0 & UC & Lymphocytic colitis & - \\
\hline 3 & 54 & M & 48 & UC & UC & Left sided \\
\hline 4 & 48 & M & 4 & UC & UC & Pancolitis \\
\hline 5 & 43 & $\mathrm{~F}$ & 260 & UC & UC & Left sided \\
\hline 6 & 25 & M & 0 & UC & Infectious colitis & - \\
\hline 7 & 63 & $\mathrm{~F}$ & 54 & UC & UC & Left sided \\
\hline 8 & 71 & $\mathrm{~F}$ & 1 & UC & UC & Pancolitis \\
\hline 9 & 59 & M & 74 & UC & UC* & Left sided \\
\hline 10 & 78 & $\mathrm{~F}$ & 12 & UC & UC & Left sided \\
\hline 11 & 21 & $\mathrm{~F}$ & 1 & $\mathrm{CD}+$ & $C D$ & A1 L3 B2 \\
\hline 12 & 39 & M & 250 & $C D$ & $C D$ & A1 L3 B3 \\
\hline 13 & 37 & M & 174 & $C D$ & $C D$ & A1 L1 B3 \\
\hline 14 & 33 & M & 32 & $C D$ & $C D$ & A1 L4 B2 \\
\hline 15 & 55 & $\mathrm{~F}$ & 18 & $C D$ & $C D$ & A2 L1 B3 \\
\hline 16 & 35 & $\mathrm{~F}$ & 1 & $C D$ & $C D$ & A1 L2 B2 \\
\hline 17 & 28 & $\mathrm{~F}$ & 66 & $C D$ & $C D$ & A1 L2 B2 \\
\hline 18 & 19 & $\mathrm{~F}$ & 26 & $C D$ & $C D$ & $A 1$ L3 Bl \\
\hline 19 & 47 & M & 110 & $C D$ & $C D$ & A1 L3 B2 \\
\hline 20 & 19 & M & 28 & $C D$ & $C D$ & $\mathrm{~A} 1 \mathrm{L4} \mathrm{B} 1$ \\
\hline 21 & 31 & $\mathrm{~F}$ & 242 & $C D$ & $C D$ & A1 L3 B3 \\
\hline 22 & 37 & $\mathrm{~F}$ & 54 & $C D$ & $C D$ & Al L3 B3 \\
\hline $\begin{array}{l}\text { UC, ulce } \\
{ }^{*} \text { Macros } \\
\text { †CD wo }\end{array}$ & $\begin{array}{l}\text { ive c } \\
\text { ically } \\
\text { iagne }\end{array}$ & $C D_{1}$ & hn's dise & classificati & healed granular & in chronic UC. \\
\hline
\end{tabular}

(Magnevist; Schering, Berlin, Germany) were applied rectally on tolerance to distend and contrast the colon. To reduce bowel motion and distend the colon before the scan, $40 \mathrm{mg}$ of N-butyl-scopolamine (Buscopan; Boehringer, Ingelheim, Germany) were given intravenously. MRI studies were performed using a $1.5 \mathrm{~T}$ Magnetom Symphony system (Siemens, Erlangen, Germany) with $20 \mathrm{mT} / \mathrm{m}$ gradients employing a circular polarised phased array body coil. Three dimensional-Flash sequences (TR/TE 4.6/1.8 ms; flip angle $25^{\circ}$; slab thickness $140-160 \mathrm{~mm}$ with 80 partitions; $512 \times 210$ matrix; field of view $400 \mathrm{~mm}$; acquisition time 28 seconds; voxel size depending on slab thickness $1.4-1.6 \mathrm{~mm}$ ) were acquired in the prone and supine positions for three dimensional reconstructions and virtual colonoscopy. Additionally, T2 weighted axial HASTE and coronal TrueFISP and two dimensional-Flash sequences were acquired before intravenous contrast application. Then we applied $0.1 \mathrm{mmol} / \mathrm{kg}$ body weight Gd-DTPA (Magnevist; Schering) intravenously in a bolus dose followed by fat suppressed axial and coronal $\mathrm{Tl}$ weighted two dimensional-Flash. Scanner time for all sequences, including rectal contrast application, was approximately 26 minutes (range 23-37).

After the MRI examination all patients underwent conventional colonoscopy.

All MR images, including the three dimensional reconstructions with virtual flights through the colon, were assessed by two blinded radiologists and a gastroenterologist in consensus. The colon was subdivided in seven segments (rectum, sigma, descending colon, transverse colon, ascending colon, caecum, and terminal ileum). Although the terminal ileum is not a part of the colon, we included it in our evaluation because it is most frequently affected in IBD and can be evaluated by conventional colonoscopy. Image and distension quality (0: non diagnostic; 1 : fair quality; 2 : good quality) and diagnosis for each part of the colon were assessed, respectively. Bowel segments were considered "non-diagnostic" if more than $50 \%$ of the segment was not adequately distended or image impression was disturbed by motion artefacts. "Fair quality" represents segment distension from $50 \%$ to $80 \%$ without major motion artefacts while "good quality" describes a bowel segment distended more than $80 \%$ without any image artefacts. Active inflammation was diagnosed when there was bowel wall thickening with contrast enhancement. ${ }^{11}$ Contrast enhancement was judged comparing the coronal two dimensional-Flash sequences before and after intravenous contrast application. Additionally, mesenteric injection and enlarged lymph nodes contributed to the diagnosis of inflammation. Derived from these features inflammation was assessed for each colonic segment assigning 0 for "no inflammation" and 2 for "inflammation" when at least two typical MRI signs of inflammation were present. "Mild inflammation" was assigned with " 1 " when there was only one typical MRI sign for inflammation.

Employing the three dimensional-Flash sequences, a volume rendered external view as well as a virtual flight

Table 2 Distension and diagnostic quality of magnetic resonance imaging (MRI) based colonography in 22 patients with known inflammatory bowel disease

\begin{tabular}{llllllll}
\hline $\begin{array}{l}\text { Filling/distension } \\
\text { in MRI } \\
\text { colonography }\end{array}$ & $\begin{array}{l}\text { Terminal } \\
\text { ileum }\end{array}$ & Caecum & $\begin{array}{l}\text { Ascending } \\
\text { colon }\end{array}$ & $\begin{array}{l}\text { Transverse } \\
\text { colon }\end{array}$ & $\begin{array}{l}\text { Descending } \\
\text { colon }\end{array}$ & $\begin{array}{l}\text { Sigmoid } \\
\text { colon }\end{array}$ & Rectum \\
\hline $\begin{array}{l}\text { Good } \\
\text { Fair }\end{array}$ & 18 & 17 & 13 & 11 & 19 & 19 & 22 \\
Insufficient & 3 & 3 & 8 & 11 & 3 & 3 & 0 \\
& 1 & 2 & 1 & 0 & 0 & 0 & 0
\end{tabular}

In the ascending and transverse colon in particular, fair filling and quality was achieved because of residual faeces and air. 
Table 3 Assessment of inflammation of the terminal ileum and colon in 10 patients with suspected or proven ulcerative colitis

\begin{tabular}{|c|c|c|c|c|c|c|c|}
\hline $\begin{array}{l}\text { Patient } \\
\text { No }\end{array}$ & $\begin{array}{l}\text { Terminal } \\
\text { ileum }\end{array}$ & Caecum & $\begin{array}{l}\text { Ascending } \\
\text { colon }\end{array}$ & $\begin{array}{l}\text { Transverse } \\
\text { colon }\end{array}$ & $\begin{array}{l}\text { Descending } \\
\text { colon }\end{array}$ & $\begin{array}{l}\text { Sigmoid } \\
\text { colon }\end{array}$ & Rectum \\
\hline \multirow[t]{2}{*}{1} & $0+$ & $0+$ & 1 & 1 & 1 & 1 & 1 \\
\hline & 2 & 2 & 2 & 2 & 2 & 2 & 2 \\
\hline \multirow[t]{2}{*}{2} & 1 & 1 & 1 & 0 & 0 & 0 & 0 \\
\hline & 0 & 0 & 0 & 0 & 0 & 0 & 0 \\
\hline \multirow[t]{2}{*}{3} & 0 & 0 & 0 & 0 & 0 & 1 & $0+$ \\
\hline & - & 0 & 0 & 0 & 0 & 2 & 2 \\
\hline \multirow[t]{2}{*}{4} & 0 & 1 & 2 & 2 & 2 & 2 & 2 \\
\hline & 1 & 2 & 2 & 2 & 2 & 2 & 2 \\
\hline \multirow[t]{2}{*}{5} & 0 & 0 & 0 & 0 & 0 & 0 & 0 \\
\hline & 0 & 0 & 0 & 0 & 1 & 1 & 1 \\
\hline \multirow[t]{2}{*}{6} & 0 & 0 & 0 & 0 & 0 & 0 & 0 \\
\hline & 0 & 1 & 0 & 0 & 0 & 0 & 1 \\
\hline \multirow[t]{2}{*}{7} & 0 & 0 & 0 & 0 & 1 & 1 & 1 \\
\hline & 0 & 0 & 0 & 0 & 2 & 2 & 1 \\
\hline \multirow[t]{2}{*}{8} & 0 & $0+$ & $0+$ & $0+$ & $0+$ & 1 & 1 \\
\hline & - & 2 & 2 & 2 & 2 & 1 & 1 \\
\hline \multirow[t]{2}{*}{9} & 0 & 0 & 0 & 0 & 0 & 0 & 0 \\
\hline & 0 & 0 & 0 & 0 & $0^{*}$ & 0 * & 0 * \\
\hline \multirow[t]{2}{*}{10} & 0 & 0 & 0 & 0 & 2 & 2 & 1 \\
\hline & 0 & 0 & 0 & 1 & 1 & 2 & 1 \\
\hline \multicolumn{8}{|c|}{$\begin{array}{l}\text { The first line of each patient describes the results based on magnetic resonance imaging examinations. The second } \\
\text { line (in bold italics) represents the inflammatory assessment based on conventional colonoscopy as the gold } \\
\text { standard: 0: no inflammation; 1: mild inflammation; } 2 \text { : inflammation. } \\
\text { "Macroscopically normal mucosa, histologically typical picture of healed granular mucosa in chronic UC. } \\
\text { tDifference between "no inflammation" and "inflammation" (0 or 2). }\end{array}$} \\
\hline
\end{tabular}

through the colon was created. After evaluation of the MR images and the virtual flight through, the radiological findings were judged against the findings of conventional colonoscopy. Conventional colonoscopy was performed by two experienced endoscopists (HCR, HH). Colonic inflammation of each bowel segment found in conventional colonoscopy was identically coded: 0 for "no inflammation", 1 for "mild inflammation", and 2 for "inflammation". "Mild inflammation" was defined by erythema, decreased or absent vascular pattern, friability of the mucosa, single or multiple aphthous lesions, and small ulcers. "Inflammation" was characterised by the presence of spontaneous bleeding and large ulcerous lesions, nodules, and/or narrowing.

\section{RESULTS}

We examined 22 patients with suspected or already proven CD and ulcerative colitis (UC) (table 1). Two of the 22 patients had findings similar to UC but were later classified as infectious or unspecific colitis, respectively. Applying MRI colonography, $77.3 \%$ (119/154 segments) of all scanned colonic segments were assessed as "good" and 20.1\% (31/ 154 segments) were considered "fair" regarding diagnostic quality and distension (table 2 ). Only $2.6 \%$ of all segments (4/154 segments) were considered "non-diagnostic" due to residual faeces resulting in non-adequate distension (one terminal ileum, two caecum, one ascending colon). Equally, in conventional colonoscopy, 2.6\% (4/154 segments) of the colon could not be classified. In one patient with $\mathrm{CD}$ the terminal ileum and caecum could not be inspected by conventional colonoscopy because of a stenosis (patient No 11) whereas in two patients with UC (patient Nos 3 and 8) the terminal ileum could not be intubated due to technical problems.

Regarding different colonic segments in MRI, we found a fair diagnostic quality and distension, especially in the ascending (13.6\%) and transverse colon (36.4\%), mainly
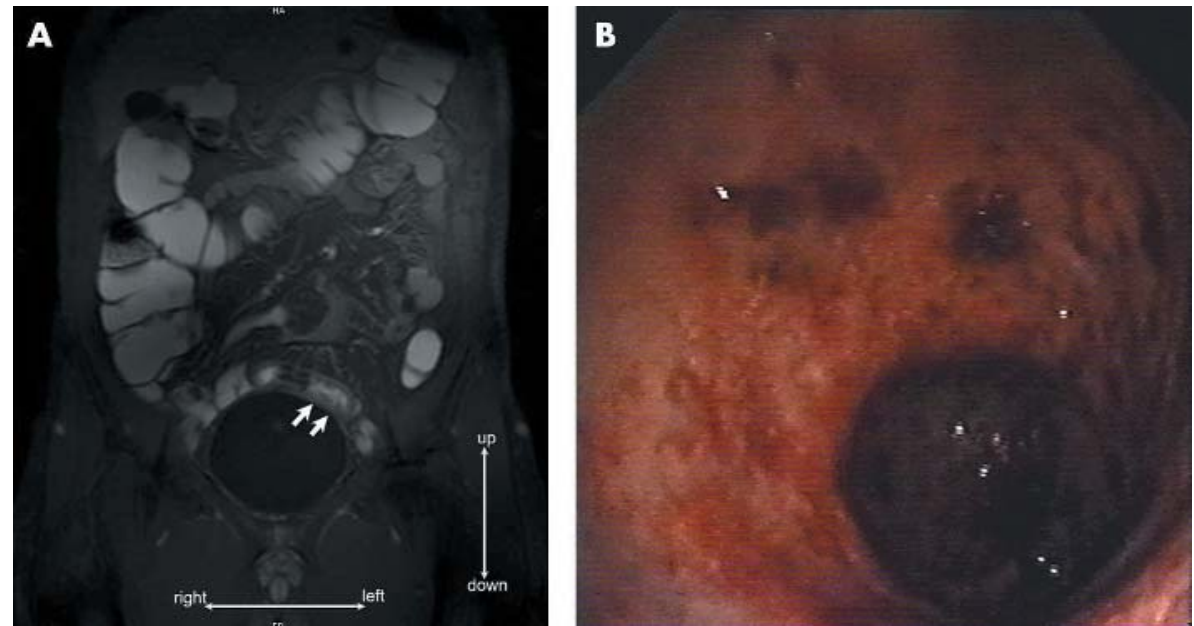

Figure 1 (A) Wall thickening (double arrow) of the sigmoid colon (fat saturated coronal two dimensional-Flash after Gd-DTPA injection) in a patient with left sided ulcerative colitis (patient No 3) without relevant contrast uptake. (B) Conventional colonoscopy of the same patient (patient No 3) showed extensive mucosal oedema, ulcers, and spontaneous bleeding in the sigmoid colon. 

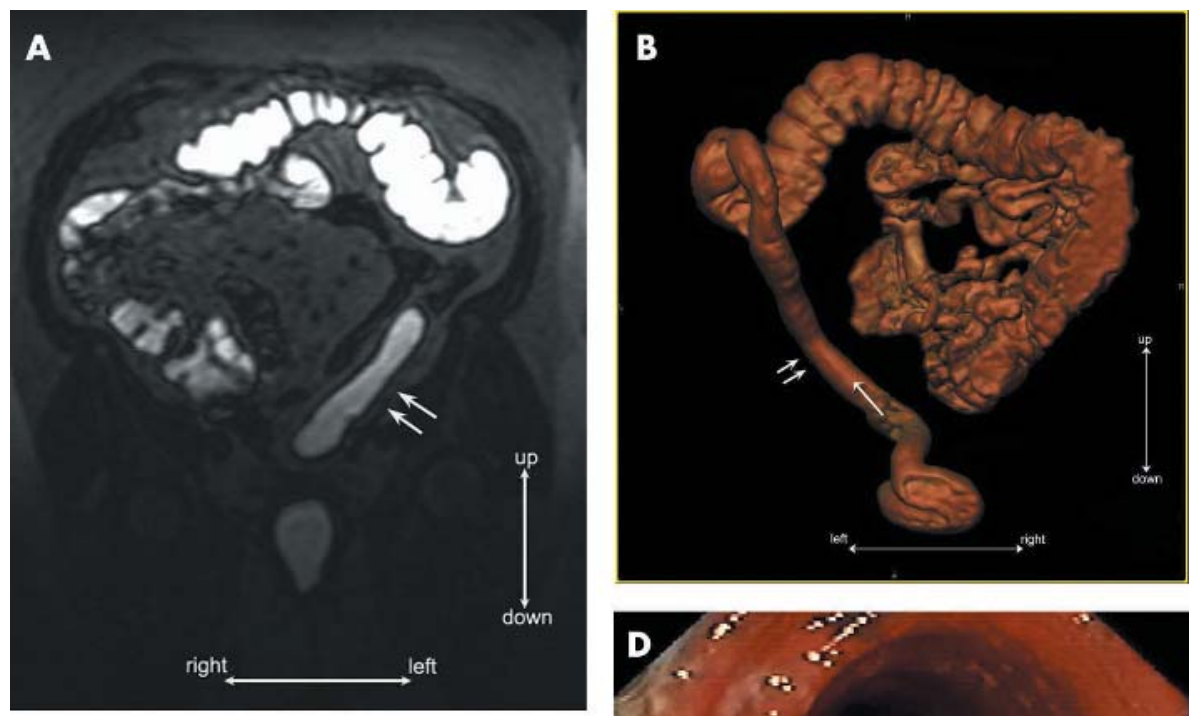

Figure 2 (A) Coronal three dimensional-Flash of a patient with ulcerative colitis (UC) (patient No 7). Burned out colitis of the descending colon (double arrows). (B) Three dimensional volume rendered reconstruction of the data set in $(A)$ with a view from the posterior. The tubular structure of the burned out descending colon (double arrows) was visualised impressively. The long arrow within the distal descending colon represents the viewpoint of the virtual camera (C). (C) Virtual intraluminal view in UC looking towards a burned out descending colon (orientation see (B)). (D) Endoscopic appearance of the left colon of the same patient as demonstrated in $(\mathrm{A}-\mathrm{C})$.
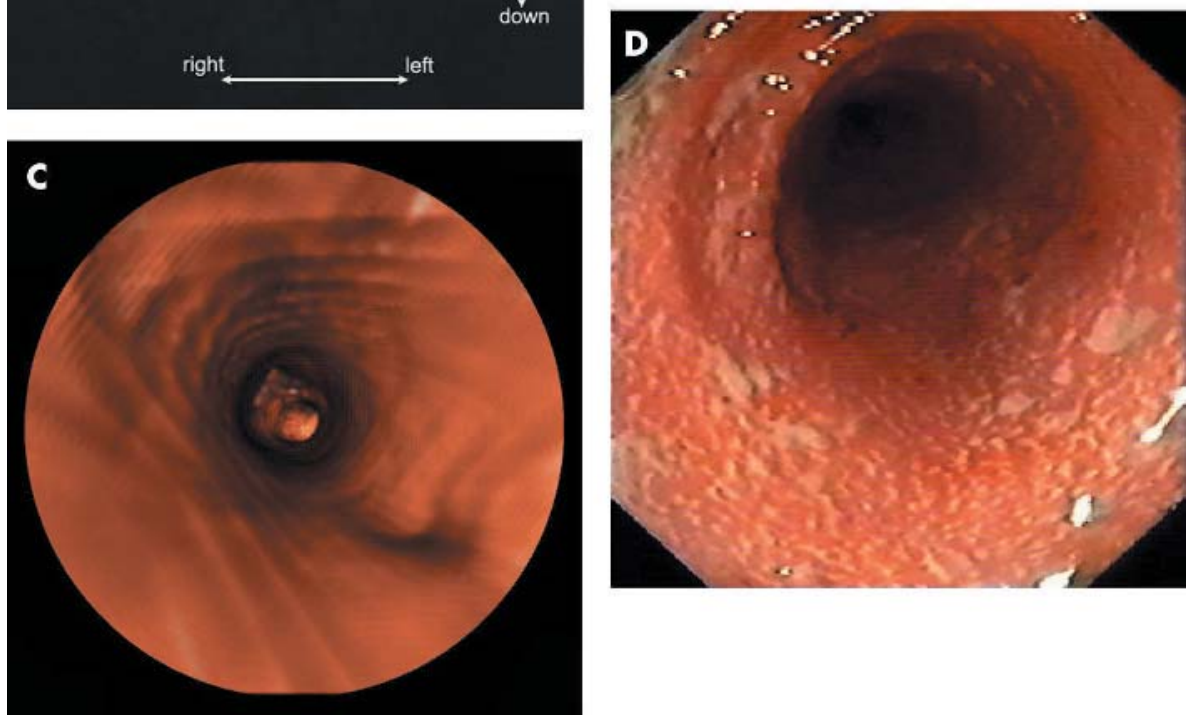

because of residual air and faeces in these bowel segments in the supine position. However, even when the colonic segments were not entirely filled, the bowel wall could be sufficiently assessed after intravenous injection of gadolinium because the remaining air acted as a negative contrast.

\section{Ulcerative colitis}

In 8 of 10 patients with known or suspected UC, signs of inflammation were found in at least one colonic segment colonoscopically. MRI based colonography in six of these eight patients found at least one colonic segment which showed the defined MRI criteria for inflammation (including the two different graduations for inflammation) (table 3). Considering each colonic segment separately, we achieved a sensitivity of $58.8 \%$ and a specificity of $91.4 \%$.

In $58.6 \%(41 / 70)$ of all colonic segments we observed identical results for MRI based colonography and conventional colonoscopy with regard to inflammation grading. In $14.3 \%(10 / 70)$ of all segments, inflammation was graded differently (fig 1) while in $24.2 \%(17 / 70)$ the presence or absence of inflammation was judged inaccurately. Regarding the 17 incorrectly assessed segments, seven segments were described as severely inflamed by conventional colonoscopy whereas the same segments were assessed as not inflamed by MRI. The virtual flight through the colon did not add any relevant diagnostic information. Inflammation assessment and grading were performed mainly based on contrast uptake and thickening of the colonic wall on sectional imaging which could not be appreciated using the intraluminal virtual endoscopic view. In two cases the external volume rendered view gave an impressive image with a rarefication of bowel folds and a tubular appearance of the colon (fig 2). In one patient two polyps in the caecum, which were overlooked in sectional MRI reading, were visualised after applying virtual colonoscopy. Both polyps, having a diameter of $1.5 \mathrm{~cm}$, were confirmed at conventional colonoscopy.

\section{Crohn's disease}

In all 12 patients with suspected $\mathrm{CD}$ at least one inflamed segment of the colon or the terminal ileum had signs of inflammation, as assessed by conventional colonoscopy. In 10 of these 12 patients MRI based colonography detected at least one inflamed segment (table 4). In two patients (patient Nos 13 and 14) MRI based colonography could not demonstrate any inflammatory signs whereas colonoscopically mild bowel inflammation was described in at least one of the segments. Sensitivity for the detection of inflammation based on each colonic segment was $31.6 \%$ with a specificity of $100 \%$ compared with conventional colonoscopy.

In MRI based colonography, 65.5\% (55/84) of all colonic segments had identical results to conventional colonoscopy. Only in one of 84 segments (1.2\%) was there underestimation in assessing an inflamed terminal ileum as a mild inflammation using MRI colonography. In 30.9\% (26/84) of all colonic segments there was complete disagreement in assessing inflammation of the colon. Analysing these 26 colonic segments there was only one segment in which severe 
Table 4 Assessment of inflammation of the terminal ileum and the colon in 12 patients with known Crohn's disease

\begin{tabular}{|c|c|c|c|c|c|c|c|}
\hline $\begin{array}{l}\text { Patient } \\
\text { No }\end{array}$ & $\begin{array}{l}\text { Terminal } \\
\text { ileum }\end{array}$ & Caecum & $\begin{array}{l}\text { Ascending } \\
\text { colon }\end{array}$ & $\begin{array}{l}\text { Transverse } \\
\text { colon }\end{array}$ & $\begin{array}{l}\text { Descending } \\
\text { colon }\end{array}$ & $\begin{array}{l}\text { Sigmoid } \\
\text { colon }\end{array}$ & Rectum \\
\hline \multirow[t]{2}{*}{11} & 2 & 2 & 2 & 0 & 0 & 0 & 0 \\
\hline & - & - & 2 & 0 & 0 & 0 & 0 \\
\hline \multirow[t]{2}{*}{12} & 1 & 0 & 0 & 0 & 0 & 0 & 0 \\
\hline & 2 & 0 & 0 & 0 & 0 & 1 & 0 \\
\hline \multirow[t]{2}{*}{13} & 0 & 0 & 0 & 0 & 0 & 0 & 0 \\
\hline & 0 & 0 & 0 & 1 & 1 & 1 & 1 \\
\hline \multirow[t]{2}{*}{14} & 0 & 0 & 0 & 0 & 0 & 0 & 0 \\
\hline & 1 & 0 & 0 & 0 & 0 & 0 & 0 \\
\hline \multirow[t]{2}{*}{15} & 2 & 0 & 0 & 0 & 0 & 0 & 0 \\
\hline & 2 & 0 & 0 & 0 & 0 & 0 & 0 \\
\hline \multirow[t]{2}{*}{16} & 0 & 0 & 0 & 0 & 1 & 0 & 0 \\
\hline & 0 & 1 & 1 & 1 & 1 & 1 & 0 \\
\hline \multirow[t]{2}{*}{17} & 0 & 0 & 0 & 1 & 0 & 0 & 0 \\
\hline & 0 & 0 & 0 & 1 & 1 & 1 & 1 \\
\hline \multirow[t]{2}{*}{18} & 2 & 0 & 0 & 0 & 0 & 0 & 0 \\
\hline & 2 & 1 & 1 & 1 & 1 & 1 & 1 \\
\hline \multirow[t]{2}{*}{19} & 2 & 0 & 0 & 0 & 0 & 0 & 0 \\
\hline & 2 & 0 & 0 & 0 & 0 & 0 & 0 \\
\hline \multirow[t]{2}{*}{20} & 2 & 0 & 0 & 0 & 0 & 0 & $0+$ \\
\hline & 2 & 1 & 1 & 1 & 1 & 1 & 2 \\
\hline \multirow[t]{2}{*}{21} & 2 & 0 & 0 & 0 & 0 & 0 & 0 \\
\hline & 2 & 0 & 0 & 0 & 0 & 0 & 0 \\
\hline \multirow[t]{2}{*}{22} & 2 & 0 & 0 & 0 & 0 & 0 & 0 \\
\hline & 2 & 0 & 0 & 0 & 0 & 1 & 0 \\
\hline
\end{tabular}

inflammation (patient No 20, rectum) was not diagnosed by MRI based colonography. The other 25 segments not correctly assessed by MRI (fig 3) were described as being mildly inflamed by conventional colonoscopy.

In one patient (patient No 11) the terminal ileum, caecum, and ascending colon were not evaluated by conventional colonoscopy because of a stenosis in the ascending colon. These segments were assessed as inflamed by MRI colonography. The patient underwent surgery and severe inflammation in the last centimetres of the terminal ileum, ileocaecal valve, as well as of the ascending colon was seen macroscopically and histologically.

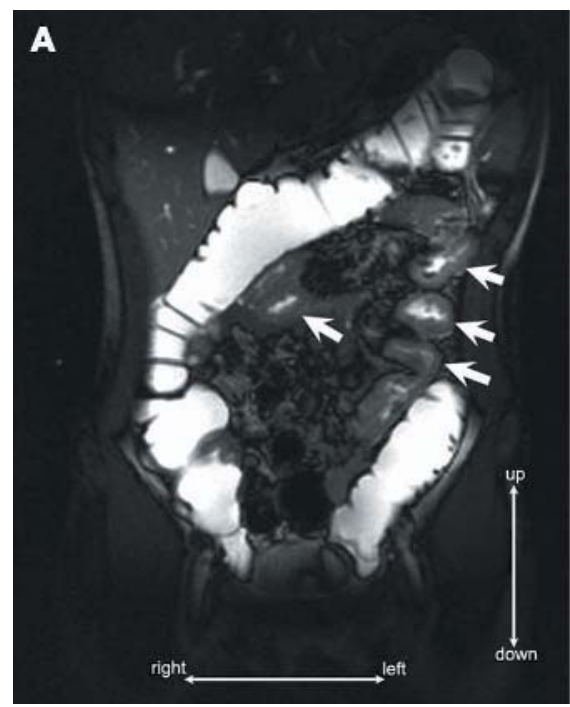

Virtual endoscopy was not of any particular use in patients with CD. Again, colonic wall thickening or increased uptake of contrast media was not visualised on three dimensional intraluminal images.

\section{DISCUSSION}

Identifying minimal or non-invasive imaging techniques to assess the intestine in IBD seems to be a promising pursuit. In small bowel imaging in particular, the results of the MRI based technique are intriguing. ${ }^{12}{ }^{13}$ To date, MRI enteroclysis appears to be a new standard to evaluate the small bowel, especially in patients with IBD. ${ }^{14-17}$ In addition, the high

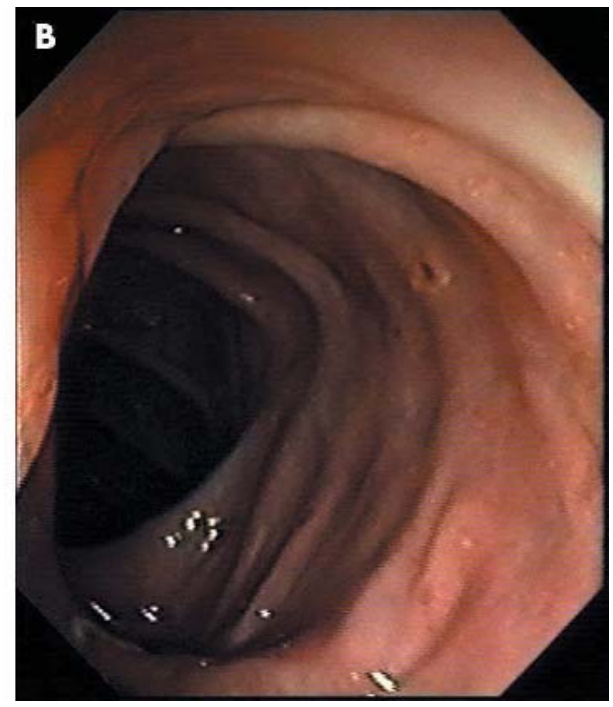

Figure 3 (A) Patient with Crohn's disease (CD) (patient No 20) and typical skip lesions (arrows) of the jejunum. The colon, which had a mild inflammation endoscopically, had a normal appearance on magnetic resonance imaging colonography. (B) Conventional colonoscopy of the same patient with CD revealed mucosal erythema and several small ulcers in the sigmoid colon (representative of similar findings in the rest of the colon of patient No 20). 
sensitive and specific diagnosis of extraluminal pathologies, ${ }^{18-20}$ such as abscesses or fistulas, with lack of ionising radiation, makes MRI a comprehensive examination tool for patients with IBD.

Colonic assessment in patients with IBD has been done in only a few studies and these have compared mostly clinical parameters such as the Crohn's disease activity index or laboratory parameters such as $\mathrm{C}$ reactive protein and white blood cell count. Madsen and colleagues ${ }^{21}$ and Maccioni and colleagues $^{22}$ found some correlation between these parameters and MRI indicators of inflammation, such as wall thickening and wall contrast uptake. Contrary to these results, Schunk and colleagues ${ }^{23}$ found no correlation between laboratory parameters and MRI findings.

A study by Koh and colleagues ${ }^{24}$ compared the findings of MRI with endoscopy or surgery, resulting in a sensitivity of $59 \%$ for identification of all bowel segments that showed active inflammation. On a per patient basis, an overall sensitivity of $91 \%$ and a specificity of $71 \%$ for the detection of active bowel disease were achieved. Our results in CD agree with these studies, even though we had a sensitivity of only $31.6 \%$ for correct assessment of the inflamed segment.

In general, we cannot recommend MRI colonography for accurately describing the location and severity of intestinal inflammation in patients with CD. While a better correlation with conventional colonoscopy in macroscopically severely inflamed segments was achieved (only one of eight was judged as non-inflamed), macroscopically mildly inflamed mucosa very often was not correctly diagnosed by MRI colonography (only two of 27 segments with colonoscopically mild inflammation were detected by MRI).

In UC, a study from an Italian group ${ }^{25}$ evaluated an orally applied superparamagnetic contrast agent without any rectal colonic distension. The authors concluded from their results that MRI with negative superparamagnetic oral contrast is comparable with endoscopy for the assessment of UC. Our results were slightly different, revealing a sensitivity of $58.8 \%$ in assessing segmental inflammation compared with colonoscopy. In two cases of endoscopically proven severe acute colitis we were unable to see any colonic bowel wall alteration using the MR imaging technique. This could be due to the exclusive mucosal inflammation in UC whereas the bowel wall is often not affected, resulting in weak contrast uptake of the bowel wall.

The recently introduced "dark lumen" technique in which a low intraluminal signal is gained by applying a Tl negative medium such as water or barium, seems to be an attractive technique in small bowel imaging and polyp assessment. ${ }^{26-28}$ By applying a $\mathrm{Tl}$ positive contrast agent (for example, GdDTPA) intravenously, the bowel wall appears with a high signal, which makes tumours or wall inflammation better discernible. The debate is still open as to whether positive (as used in our study) or negative intraluminal contrast is superior in IBD assessment. In patients with IBD in particular, positive intraluminal contrast allows better discrimination of positively contrasted bowel lumen from extraluminal pathological findings such as abscesses, which appear similar to water on MRI. In addition, the intraluminal contrast signal in our technique is much stronger than the signal of contrast uptake by the bowel, allowing adequate differentiation between the bowel wall and the intestinal lumen.

Three dimensional reconstructions with intra- and extraluminal views, so-called "virtual colonoscopy", are a fascinating image processing tool. Currently its value in CT and MRI colonography is as a troubleshooter in dubious appearing regions when reading the primary source images with multiplanar reconstructions. In our study, the virtual flight through did not provide any relevant additional diagnostic information. Bowel wall pathologies such as thickening or contrast enhancement are not visualised with conventional three dimensional techniques. Analogous to a recently published study ${ }^{29}$ comparing CT based colonography with conventional colonoscopy in assessing strictures in patients with CD after surgery, we were unable to visualise subtle intraluminal changes by virtual endoscopy. However, the three dimensional external views gave an impressive visualisation of chronic "burned out" colitis revealing the typical tubular appearance of fold rarefication.

In this study we did not evaluate patient preference towards both procedures. Several studies have addressed this issue and demonstrated that patients in general prefer virtual colonoscopy. Probably the most embarrassing procedure during virtual colonoscopy is colonic insufflation with air, carbon dioxide, or enemas containing contrast media to achieve maximal colonic distension, ${ }^{1}{ }^{30-34}$ which also has to be performed in the case of the "dark lumen" technique. However, patients judge the bowel cleansing as the most negative experience but bowel cleansing has to be performed for virtual colonoscopy as well as colonoscopy. ${ }^{33}$

Recently, Johnson et al demonstrated considerable interobserver variability for CT colonography with kappa statistic values ranging from -0.67 to $0.89 .{ }^{35}$ However, this interobserver variability refers solely to sensitivity and specificity values for detection of colonic polyps and cannot be applied to demonstration of typical radiological signs of inflammation. However, in larger cohorts with healthy controls as well as in patients with inflammatory bowel disease, interobserver variability should be addressed.

In conclusion, MRI colonography, applying positive rectal contrast medium, cannot replace conventional colonoscopy in the evaluation of IBD. In particular, the low sensitivity in accurately detecting mild colonic inflammation, as often seen in patients with UC or CD, hampers its value for clinical use. However, in the near future newer techniques such as colour coding of colonic wall thickness or different contrast media as well as better spatial resolution may improve the sensitivity of MR colonography for inflammation in patients with IBD. ${ }^{26} 36$

\section{ACKNOWLEDEGMENTS}

The work was supported by DCCV eV, Leverkusen, Germany (German Crohn's Disease and Ulcerative Colitis Association).

\section{Authors' affiliations}

A G Schreyer, M Völk, S Feuerbach, J Seitz, Department of Radiology, University Hospital Regensburg, Germany

H C Rath, J Schölmerich, G Rogler, H Herfarth, Department of Internal Medicine I, University Hospital Regensburg, Germany

R Kikinis, Department of Radiology, Brigham and Women's Hospital, Harvard Medical School, Boston, MA, USA

Conflict of interest: None declared.

\section{REFERENCES}

1 Thomeer M, Bielen D, Vanbeckevoort D, et al. Patient acceptance for CT colonography: what is the real issue? Eur Radiol 2002;12:1410-15.

2 Fenlon HM, Nunes DP, Schroy PC, et al. A comparison of virtual and conventional colonoscopy for the detection of colorectal polyps. N Engl J Med 1999:341:1496-503.

3 Luboldt W, Fletcher JG, Vogl TJ. Colonography: current status, research directions and challenges. Update 2002. Eur Radiol 2002;12:502-24.

4 Jolesz FA, Lorensen WE, Shinmoto $H$, et al. Interactive virtual endoscopy. AJR Am J Roentgenol 1997;169:1229-35.

5 Vining DJ, Gelfand DW, Bechtold RE, et al. Technical feasibility of colon imaging with helical CT and virtual reality. AJR Am J Roentgenol 1994;162(suppl): 104.

6 Luboldt W, Baverfeind P, Steiner P, et al. Preliminary assessment of threedimensional magnetic resonance imaging for various colonic disorders. Lancet 1997:349:1288-91

7 Pickhardt PJ, Choi JR, Hwang I, et al. Computed tomographic virtual colonoscopy to screen for colorectal neoplasia in asymptomatic adults. N Engl J Med 2003;349:2191-200. 
8 Dachman $\mathrm{AH}$, Yoshida $\mathrm{H}$. Virtual colonoscopy: past, present, and future. Radiol Clin North Am 2003;41:377-93.

9 Fenlon HM, McAneny DB, Nunes DP, et al. Occlusive colon carcinoma: virtual colonoscopy in the preoperative evaluation of the proximal colon. Radiology 1999:210:423-8.

10 Gasche C, Scholmerich J, Brynskov J, et al. A simple classification of Crohn's disease: report of the Working Party for the World Congresses of Gastroenterology, Vienna 1998. Inflamm Bowel Dis 2000;6:8-15.

11 Madsen SM, Thomsen HS, Munkholm P, et al. Active Crohn's disease and ulcerative colitis evaluated by low-field magnetic resonance imaging. Scand J Gastroenterol 1998;33:1193-200.

12 Umschaden HW, Szolar D, Gasser J, et al. Small-bowel disease: comparison of MR enteroclysis images with conventional enteroclysis and surgical findings. Radiology 2000;215:717-25.

13 Schreyer AG, Herfarth H, Kikinis R, et al. 3D modeling and virtual endoscopy of the small bowel based on magnetic resonance imaging in patients with inflammatory bowel disease. Invest Radiol 2002;37:528-33.

14 Aschoff AJ, Zeitler H, Merkle EM, et al. MR enteroclysis for nuclear spin tomographic diagnosis of inflammatory bowel diseases with contrast enhancement. Rofo Fortschr Geb Rontgenstr Neven Bildgeb Verfahr 1997; 167:387-91.

15 Rieber A, Wruk D, Potthast S, et al. Diagnostic imaging in Crohn's disease: comparison of magnetic resonance imaging and conventional imaging methods. Int J Colorectal Dis 2000;15:176-81.

16 Rieber A, Nussle K, Reinshagen M, et al. MRI of the abdomen with positive oral contrast agents for the diagnosis of inflammatory small bowel disease. Abdom Imaging 2002;27:394-9.

17 Holzknecht N, Helmberger T, von Ritter C, et al. MRI of the small intestine with rapid MRI sequences in Crohn disease after enteroclysis with oral iron particles. Radiologie 1998;38:29-36.

18 Koelbel G, Schmiedl U, Majer MC, et al. Diagnosis of fistulae and sinus tracts in patients with Crohn disease: value of MR imaging. AJR Am J Roentgenol 1989;152:999-1003

19 Hussain SM, Outwater EK, Joekes EC, et al. Clinical and MR imaging features of cryptoglandular and Crohn's fistulas and abscesses. Abdom Imaging 2000;25:67-74.

20 Bell SJ, Halligan S, Windsor AC, et al. Response of fistulating Crohn's disease to infliximab treatment assessed by magnetic resonance imaging. Aliment Pharmacol Ther 2003;17:387-93.

21 Madsen SM, Thomsen HS, Munkholm P, et al. Inflammatory bowel disease evaluated by low-field magnetic resonance imaging. Comparison with endoscopy, 99mTc-HMPAO leucocyłe scintigraphy, conventional radiography and surgery. Scand J Gastroenterol 2002;37:307-16.
22 Maccioni F, Viscido A, Broglia L, et al. Evaluation of Crohn disease activity with magnetic resonance imaging. Abdom Imaging 2000;25:219-28.

23 Schunk K, Kern A, Oberholzer K, et al. Hydro-MRI in Crohn's disease: appraisal of disease activity. Invest Radiol 2000;35:431-7.

24 Koh DM, Miao Y, Chinn RJ, et al. MR imaging evaluation of the activity of Crohn's disease. AJR Am J Roentgenol 2001;177:1325-32.

25 D'Arienzo A, Scaglione G, Vicinanza G, et al. Magnetic resonance imaging with ferumoxil, a negative superparamagnetic oral contrast agent, in the evaluation of ulcerative colitis. Am J Gastroenterol 2000;95:720-4.

26 Debatin JF, Lauenstein TC. Virtual magnetic resonance colonography. Gut 2003;52(suppl 4):17-22.

27 Lauenstein TC, Herborn CU, Vogt FM, et al. Dark lumen MR-colonography: initial experience. Rofo Fortschr Geb Rontgenstr Neuen Bildgeb Verfahr 2001;173:785-9.

28 Lavenstein TC, Debatin JF. Magnetic resonance colonography with fecal tagging: an innovative approach without bowel cleansing. Top Magn Reson Imaging 2002;13:435-44

29 Biancone L, Fiori R, Tosti C, et al. Virtual colonoscopy compared with conventional colonoscopy for stricturing postoperative recurrence in Crohn's disease. Inflamm Bowel Dis 2003;9:343-50.

30 Akerkar GA, Yee J, Hung R, et al. Patient experience and preferences toward colon cancer screening: A comparison of virtual colonoscopy and conventional colonoscopy. Gastrointest Endosc 2001:54:310-15.

31 Angtuaco TL, Banaad-Omiotek GD, Howden CW. Differing attitudes toward virtual and conventional colonoscopy for colorectal cancer screening: surveys among primary care physicians and potential patients. Am J Gastroenterol 2001;96:887-93.

32 Gluecker TM, Johnson CD, Harmsen WS, et al. Colorectal cancer screening with CT colonography, colonoscopy, and double-contrast barium enema examination: prospective assessment of patient perceptions and preferences. Radiology 2003;227:378-84.

33 Ristvedt SL, McFarland EG, Weinstock LB, et al. Patient preferences for CT colonography, conventional colonoscopy, and bowel preparation. Am J Gastroenterol 2003;98:578-85.

34 Svensson MH, Svensson E, Lasson A, et al. Patient acceptance of CT colonography and conventional colonoscopy: prospective comparative study in patients with or suspected of having colorectal disease. Radiology 2002;222:337-45.

35 Johnson CD, Harmsen WS, Wilson LA, ef al. Prospective blinded evaluation of computed tomographic colonography for screen detection of colorectal polyps. Gastroenterology 2003;125:311-19.

36 Schreyer AG, Fielding JR, Warfield SK, et al. Virtual CT cystoscopy: color mapping of bladder wall thickness. Invest Radiol 2000;35:331-4. 